\title{
PROGRESSIVE SYSTEMIC SCLEROSIS WITH MULTIPLE COMORBIDITIES IN A 71-YEAR-OLD FEMALE
}

\author{
Emran Lyutfi ${ }^{1}$, Ilia-Presian Georgiev ${ }^{1}$, Tanya Shivacheva ${ }^{2}$ \\ ${ }^{1}$ Student, Medical University of Varna \\ ${ }^{2}$ Clinic of Rheumatology, St. Marina University Hospital, Varna
}

\begin{abstract}
INTRODUCTION: Progressive systemic sclerosis (PSS) is a connective tissue disorder with unknown etiology, characterized by increased collagen deposition leading to fibrosis, skin thickening and other pathological changes in organs. Females constitute at least two-thirds of all the cases. The disease commonly occurs in women aged 30-40 years. Other features of the disease include Raynaud's phenomenon, telangiectasia, calcinosis, myositis, arthritis, tenosynovitis, renal failure, esophageal dysmotility, pulmonary fibrosis, and heart failure.
\end{abstract}

MATERIALS AND METHODS: A 71-year-old female was hospitalized with ischemic and cyanotic fingertips in the Department of Rheumatology, St. Marina University Hospital, Varna, Bulgaria. She complained of pain in both hip joints when walking, erythema in the region of the distal phalanges of the hands and feet with individual ulcerations on the fingertips. Raynaud's phenomenon was positive. Other comorbidities that were included in her medical records were type two diabetes, hypertension, and past history of endometrial cancer. The physical exam revealed sclerodactyly, cutaneous sclerosis of hands and feet, and microstomia. Laboratory tests revealed high levels of very low-density lipoprotein (4.9) and high level of blood sugar (7.2). Immunology revealed high levels of antinuclear antibodies (+++), anti-centromere protein B (++), anti-Sjögren's syndrome-A (Ro52) (+++).

RESULTS: The following medications were administered: methylprednisolone $40 \mathrm{mg}$ intravenous, ranitidine $150 \mathrm{mg}$ 2x1 per os, pulse therapy with cyclophosphamide amp $1000 \mathrm{mg}$ in $500 \mathrm{~mL}$ saline, then followed by another bank of $500 \mathrm{~mL}$ saline, metoclopramide $10 \mathrm{mg}-1$ ampoule intravenously, and heparin $2 \times 500 \mathrm{E}$ intravenous.

CONCLUSION: The occurrence of the disease in such an advanced age is unlikely, while the risk of diabetes and neoplasia increases exponentially with the age. The uniqueness of the case herein lies with its late presentation, which could easily be misinterpreted as a complication of her concomitant diseases.

Keywords: rheumatology, progressive systemic sclerosis, Raynaud's phenomenon, microstomia

\footnotetext{
Address for correspondence:

Emran Lyutfi

Medical University of Varna

55 Marin Drinov St

9002 Varna

Bulgaria

e-mail: heliacaquila@gmail.com
}

Received: September 6, 2018

Accepted: December 03, 2018 


\section{INTRODUCTION}

Systemic sclerosis (SSc) is a chronic systemic autoimmune disease characterized by microangiopathy, increased deposition of extracellular matrix with progressive fibrosis, both in the skin and in visceral organs that can involve the lungs, heart, kidneys, and the gastrointestinal tract (1).

Many factors, including environmental ones, can lead to immunologic system disturbances and vascular changes. Endothelial alterations may lead to a cascade of stimulatory changes that involve many cells, including fibroblasts, T-lymphocytes, macrophages, and mast cells. In turn, the activated cells secrete a variety of substances, including cytokines and their soluble receptors and enzymes and their inhibitors. These substances lead to changes in the extracellular matrix compounds, including fibronectin; proteoglycans; and collagen types I, III, V, and VII. Increased collagen production or disturbances in its degradation can cause excessive collagen deposition in tissues. The tissue lesions in various stages of scleroderma are charcterized by early microvascular damage, mononuclear cell infiltrates, and slowly developing fibrosis. In later stages of scleroderma, the main findings are very densely packed collagen in the dermis, loss of cells, and atrophy. Although skin fibrosis is the distinguishing hallmark, the pathological changes in the lungs, gastrointestinal tract, kidneys, and heart determine the clinical outcome. In general, the extent of skin involvement and its rate of progression reflect the severity of visceral organ complications $(2,3)$.

A striking feature of systemic sclerosis is its patient-to-patient variability, and heterogeneity has been observed in clinical manifestations, autoantibody profiles, the rate of disease progression, response to treatment and survival. Based on the extent of their skin involvement, patients are grouped into limited cutaneous systemic sclerosis (lcSSc) and diffuse cutaneous systemic sclerosis (dcSSc) subsets. In lcSSc, skin fibrosis is restricted to the fingers (sclerodactyly), distal extremities and face, whereas in dcSSc, the trunk and proximal extremities are also affected. In patients with lcSSc, Raynaud's phenomenon typically precedes skin involvement and other disease manifestations by months to years, whereas patients with dcSSc have rapid disease progression with extensive skin changes and early development of visceral organ complications (2).

Autoantibodies are particularly helpful in systemic sclerosis for both diagnosis and classification. lcSSc is more commonly associated with centromerespecific antibodies, whereas dcSSc is more often associated with topoisomerase I- or RNA polymerase III-specific antibodies. However, not all patients with systemic sclerosis fall clearly into one of these two disease subsets, and some can change their subset assignment over time (2).

\section{CASE PRESENTATION}

A 71-year-old female was hospitalized with ischemic and cyanotic fingertips in the Department of Rheumatology, St. Marina University Hospital, Varna, Bulgaria. She complained of pain in both hip joints when walking. Erythema was observed in the region of the distal phalanges of the hands and feet with individual ulcerations on the fingertips and Raynaud's phenomenon was positive. Other comor-

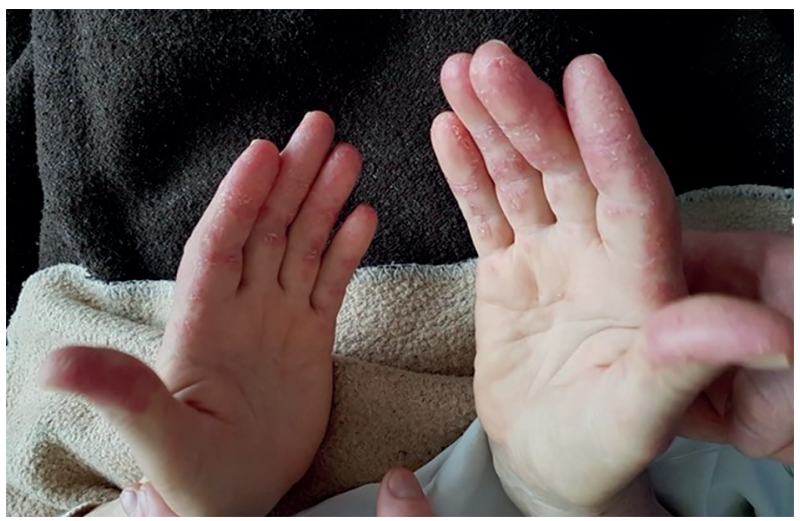

Fig. 1

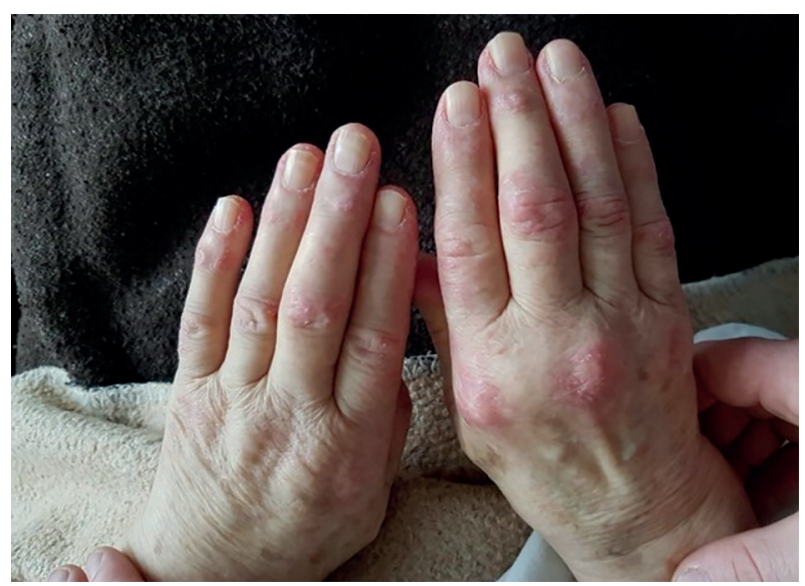

Fig. 2 


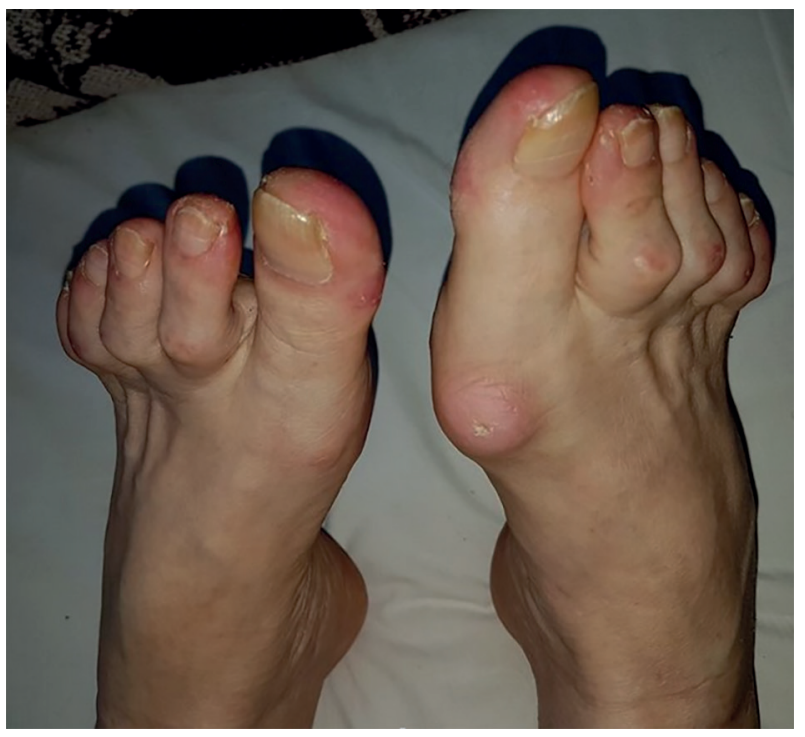

Fig. 3

bidities, which were included in her medical records, were type two diabetes, hypertension and past history of endometrial cancer. The vital signs were blood pressure of $130 / 80 \mathrm{mmHg}$, and pulse of $75 \mathrm{bpm}$. On

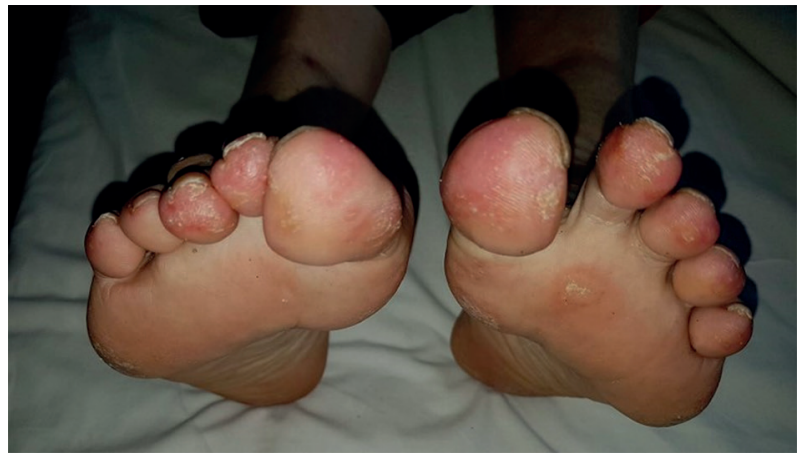

Fig. 4

physical examination the skin was pale pink, indurated and upon testing, its tightness taking hold of a plica was hindered in the area of the hands, feet, and face. The visible mucosa was without deviations. The fingers were pale with low local temperature with multiple ulcerations and indurations. Laboratory test results: Hb: 103 g/L, leukocytes: 4.22 10^9/L, platelet count: 181 10^9/L. urea: $5.5 \mathrm{mmol} / \mathrm{L}$; creatinine: $63 \mathrm{mcmol} / \mathrm{L}$; random plasma glucose: $7.1 \mathrm{mmol} / \mathrm{L}$, VLDL: 4.9; Na: $144 \mathrm{mmol} / \mathrm{L}$; K: $4.3 \mathrm{mmol} / \mathrm{L}$, CRP

Table 1

\section{ACR / EULAR Criteria For The Classification Of Systemic Sclerosis (Scleroderma)*}

\begin{tabular}{|c|c|c|}
\hline Item & Sub-items(s) & Weight/score ${ }^{t}$ \\
\hline $\begin{array}{l}\text { Skin thickening of the fingers of both hands extending proximal } \\
\text { to the metacarpophalangeal joints (sufficient criterion) }\end{array}$ & - & 9 \\
\hline Skin thickening of the fingers (only count the higher score) & $\begin{array}{l}\text { Puffy fingers } \\
\text { Sclerodactyly of the fingers (distal to the metacarpophalangeal joints } \\
\text { but proximal to the proximal interphalangeal joints) }\end{array}$ & $\begin{array}{l}2 \\
4\end{array}$ \\
\hline Fingertip lesions (only count the higher score) & $\begin{array}{l}\text { Digital tip ulcers } \\
\text { Fingertip pitting scars }\end{array}$ & 2 \\
\hline Telangiectasia & - & 2 \\
\hline Abnormal nailfold capillaries & - & 2 \\
\hline $\begin{array}{l}\text { Pulmonary arterial hypertension and/or interstitial lung disease } \\
\text { (maximum score is 2) }\end{array}$ & $\begin{array}{l}\text { Pulmonary arterial hypertension } \\
\text { Interstitial lung disease }\end{array}$ & 2 \\
\hline Raynaud's phenomenon & - & 3 \\
\hline $\begin{array}{l}\text { SSc-related autoantibodies (anticentromere, } \\
\text { anti-topoisomerase I [anti-Scl-70], anti-RNA polymerase III) } \\
\text { (maximum score is 3) }\end{array}$ & $\begin{array}{l}\text { Anticentromere } 3 \\
\text { Anti-topoisomerase I } \\
\text { Anti-RNA polymerase III }\end{array}$ & 3 \\
\hline \multicolumn{3}{|c|}{$\begin{array}{l}\text { The criteria are not applicable to patients with skin thickening sparing the fingers or to patients who have a scleroderma-like disorder that better explains } \\
\text { their manifestations (e.g., nephrogenic sclerosing fibrosis, generalized morphea, eosinophilic fasciitis, scleredema diabeticorum, scleromyxedema, } \\
\text { erythromyalgia, porphyria, lichen sclerosis, graft-versus-host disease, diabetic cheiroarthropathy). }\end{array}$} \\
\hline $\begin{array}{l}\text { The total score is determined by adding the maximum v } \\
\text { Patients with a total score of } \geq 9 \text { are classified as } \mathbf{h}\end{array}$ & $\begin{array}{l}\text { ht (score) in each category. } \\
\text { g definite scleroderma. }\end{array}$ & \\
\hline
\end{tabular}

\section{Sensitivity $91 \% \quad$ Specificity $92 \%$}

Van den Hoogen et al. 2013 Classification Criteria for Systemic Sclerosis. Arthritis and Rheumatism. Vol. 65, No. 11, November 2013, pp 2737-2747 
quantitative: $0.47 \mathrm{mg} / \mathrm{L}$; antinuclear antibodies (ANA) (+++), anti-centromere protein B (antiCEMPB) (++), anti-Sjögren's syndrome-A (Ro52) (anti-SSA) $(+++)$. Abdominal ultrasound revealed a persisting oval paraaortic lesion on the left with an approximate size of $38 / 42 \mathrm{~mm}$ and a cortical cyst in the left kidney with an approximate size of $37 / 22 \mathrm{~mm}$.

\section{RESULTS}

The following medications were administered intravenously: methylprednisolone $40 \mathrm{mg}$, ranitidine $150 \mathrm{mg} 2 \mathrm{x} 1$ per os, pulse therapy with cyclophosphamide amp $1000 \mathrm{mg}$ in $500 \mathrm{~mL}$ saline, then followed by another bank of $500 \mathrm{~mL}$ saline, metoclopramide $10 \mathrm{mg}-1$ ampoule intravenously, and heparin $2 \times 500 \mathrm{E}$.

\section{DISCUSSION}

Scleroderma is an autoimmune disorder involving multiple systems, thus making the course of this disease unpredictable. Though the exact nature of the disease is not known, high prevalence of circulating autoantibodies in serological investigations points toward an autoimmune mechanism (4).

In this case, a 71-year-old female patient was with main complaints of pain in both hip joints when walking, erythema in the region of the distal phalanges of the hands and feet with individual ulcerations on the fingertips. On physical examination, sclerosis lesions, sclerodactyly on fingers and toes, telangiectasia in the region of the hands and feet were reported.

Laboratory test results: CRP quantitative: 0.47 $\mathrm{mg} / \mathrm{L}$, antinuclear antibodies (ANA) $(+++)$, anti-centromere protein B (antiCEMP-B) $(++)$, anti-Sjögren's syndrome-A (Ro52) (anti-SS-A) (+++) with the conclusion: scleroderma.

In 2013, a revised classification criteria - the American College of Rheumatology (ACR)-European League Against Rheumatism (EULAR) criteria - were proposed to address some of the difficulties in the classification and diagnosis of scleroderma (Table 1). In this case, the patient had skin thickening of the fingers of both hands extending proximally to the metacarpophalangeal joints, sclerodactyly of the fingers, individual fingertip lesions with pitting scars, telangiectasia, Raynaud's phenomenon,
SSc-related autoantibodies, and the score was 24 . The patient was then diagnosed with scleroderma.

\section{CONCLUSION}

The management for systemic scleroderma consists of 1) counseling and psychological support; 2) management of the skin and joints; 3 ) management of Raynaud's phenomenon; 4) drug therapy; 5) immunotherapy; and 6) management of complications.

$\diamond$ Counselling and psychological support areneeded to alleviate the burden of the disease and in increasing the quality of life for the patient.

ه Methylprednisolone $40 \mathrm{mg}$ i.v. is administers as an anti-inflammatory agent.

$\diamond$ Ranitidine $150 \mathrm{mg} 2 \mathrm{x} 1$ p.o. is administered as an antiulcerative agent.

$\diamond$ Cyclophosphamide amp $1000 \mathrm{mg}$ pulse therapy is used as an immunosuppressant.

$\diamond$ Metoclopramide $10 \mathrm{mg}-1$ ampoule i.v. is used as an antiemetic.

- Heparin 2x500E i.v. is administered as an anticoagulant.

\section{REFERENCES}

1. Gabrielli A, Avvedimento Ev, Krieg T. Scleroderma. N Engl J Med. 2009; 360(19):1989-2003. doi: 10.1056/NEJMra0806188.

2. Schrier RW. Systemic sclerosis. The internal medicine case book, Real patient real answer. $3^{\text {rd }}$ ed. Lippincott Williams \& Wilkins; 2008.

3. Allanore Y, Simms R, Distler O, Trojanowska M2, Pope J, Denton CP, et al. Systemic sclerosis. Nat Rev Dis Primers. 2015;1:15002. doi: 10.1038/ nrdp.2015.2.

4. Takehara K, Sato S. Localized scleroderma is an autoimmune disorder. Rheumatology (Oxford). 2005;44(3):274-9. doi: 10.1093/rheumatology/ keh487. 